\title{
Unexpected degradation of the bisphosphonate P-C-P bridge under mild conditions
}

\author{
Petri A. Turhanen* and Jouko J. Vepsäläinen
}

\section{Full Research Paper}

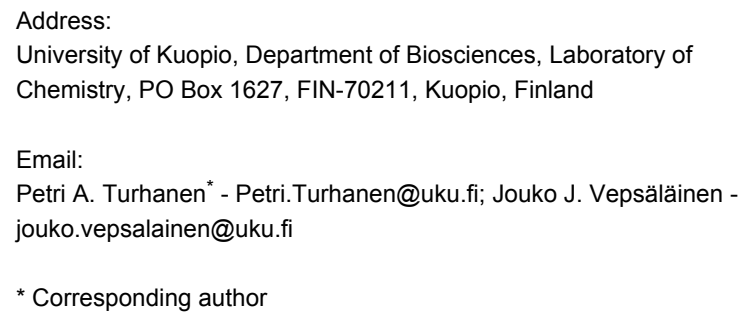

Beilstein Journal of Organic Chemistry 2008, 4, No. 7. doi:10.1186/1860-5397-4-7

Received: 08 November 2007

Accepted: 21 January 2008

Published: 21 January 2008

CC 2008 Turhanen and Vepsäläinen; licensee Beilstein-Institut. License and terms: see end of document.

\begin{abstract}
Unexpected degradation of the P-C-P bridge from novel bisphosphonate derivative 1a and known etidronate trimethyl ester (1b) has been observed under mild reaction conditions. A proposed reaction mechanism for the unexpected degradation of $\mathbf{1 a}$ and $\mathbf{1 b}$ is also reported.
\end{abstract}

\section{Background}

Bisphosphonates (BPs) are analogs of naturally occurring pyrophosphate, where the chemically and enzymatically labile P-O$\mathrm{P}$ bridge has been replaced with a P-C-P bridge, making these compounds relatively resistant to chemical hydrolysis and completely resistant to enzymatic hydrolysis (Figure 1) [1-5]. These BP compounds bind strongly to calcium phosphate and inhibit its formation, aggregation and dissolution [6]. The affinity for the bone mineral represents the basis for their use in the treatment of many diseases associated with increased bone resorption, such as metastatic bone disease, Paget's disease and osteoporosis [1-6]. As described above, the BPs have been used for decades in the therapy of bone diseases but recently these compounds have been found to be active in many other fields, such as in the treatment of parasitic diseases [7-11] and atherosclerosis [12]. Furthermore, the BPs have been shown to be effective against calcifying nanoparticles (CNPs, known also as nanobacteria) which may be responsible for several human diseases where calcium phosphate deposition is a hallmark, e.g. cardiovascular diseases, kidney stones, urological diseases, e.g. prostatitis, many cancers and various forms of autoimmune diseases $[13,14]$. Therefore it is very important to understand the chemistry of BPs in detail.<smiles>CC(O)(P(=O)(O)O)P(=O)(O)O</smiles><smiles>[R]C([R])(P(=O)(O)O)P(=O)(O)O[Na]</smiles><smiles>O=P(O)(O)OP(=O)(O)O[Nb]</smiles>

Etidronate

General structure of BPs Pyrophosphate

Figure 1: Structures of etidronate, pyrophosphate and general structure of bisphosphonates.

Etidronate, (1-hydroxyethylidene)-1,1-bisphosphonic acid (HEBPA) disodium salt, is one of the earliest synthesized and is the most extensively investigated BP compound, still being in 
clinical use today (Figure 1) [1-6,15]. Our group has designed, synthesized and studied in vitro several different etidronate and alendronate derivatives to act as biodegradable prodrugs of these drugs [16-23]. During our ongoing study to prepare new, possibly bioreversible BP derivatives, we observed unexpected degradation of the P-C-P bridge under mild reaction conditions in two of the prepared etidronate derivatives. Earlier, Szymczak et. al. [24] have described the formation of H-phosphonate (also known as phosphite) and phosphate components from a phosphonate-phosphate compound (same kind of structure as $\mathbf{8}$ in Scheme 1) either in $\mathrm{CH}_{3} \mathrm{CN} / \mathrm{Et}_{3} \mathrm{~N} / \mathrm{H}_{2} \mathrm{O}(\mathrm{v} / \mathrm{v})$ or phosphate buffer, pH 7.4 at $37{ }^{\circ} \mathrm{C}$. Szajnman et. al. [25] has reported loss of two molecules of phosphite in tetraethyl oxirane-2,2diylbis(phosphonate); however the kind of degradation which we will discuss in this paper has not been previously reported.

\section{Results and Discussion}

As mentioned in the introduction, the P-C-P bridge of BPs has been reported to be relatively stable against chemical hydrolysis, however here we report the unexpectedly easy degradation of two etidronate derivatives into acetate and phosphite moieties. In our ongoing study to prepare novel biodegradable BP derivatives, a new carbonate derivative of etidronate was synthesised. The synthesis was started from the known acetylated etidronic acid [21] (5, see Scheme 2) by treating it with ethyl chloroformate and sodium carbonate. The NMR spectroscopy results were surprising since they pointed to the formation of a novel etidronate derivative 1a (see Scheme 2). In the ${ }^{31} \mathrm{P}$ NMR spectrum, there were four doublets $(1: 1: 1: 1)$ due to the presence of two diastereomers. The ${ }^{1} \mathrm{H}$ NMR spectrum contained two complicated splitting patterns at approx. 4.46 and $4.28 \mathrm{ppm}$, their integral ratio was 1 to 3 , respectively, indicating two different kinds of $-\mathrm{OCH}_{2}$ groups in ratio 1:3. After inspection of ${ }^{13} \mathrm{C}$ NMR spectra and the ESI-MS results, we concluded that the prepared molecule had the unanticipated structure of $1 \mathrm{a}$ and not the expected structure where
$\mathrm{R}^{2}=\mathrm{R}^{3}=\mathrm{C}(\mathrm{O})$ OEt (see Scheme 2). To confirm the selective formation of 1a, the synthesis was repeated several times, but the result was always the same (formation of 1 a was observed in all experiments), though in some experiments a transesterification of the acetyl group to $\mathrm{C}(\mathrm{O}) \mathrm{OEt}$ group was observed in yields of $0-13 \%$ as confirmed by the ${ }^{1} \mathrm{H}$ and ${ }^{31} \mathrm{P}$ NMR spectra. We were unable to provide any direct explanation for the variation in the transesterification proportion. Etidronic acid was also tested as a starting material to prepare a derivative such as 1a [C(O)OEt group instead of Ac group], but the reaction did not occur under the same conditions as those used in the preparation of 1a. Our subsequent studies with derivative 1a led us to another very surprising result, which occurred when 4 equiv of $\mathrm{NaOH}\left(40 \% \mathrm{NaOH}\right.$ in $\left.\mathrm{H}_{2} \mathrm{O}\right)$ were added to the solution of $1 \mathrm{a}$ in $\mathrm{MeOH}$ and stirred for 30 minutes at room temperature. After evaporation of the reaction mixture to dryness, the residue contained almost exclusively ( $>95 \%$ degradation was observed) sodium acetate $\mathbf{6}$ and phosphites 2-4 (compound $\mathbf{4}$ can be also called phosphorous acid monosodium salt) as can be seen in Scheme 2. Compounds 2-4 were readily characterized by their $\mathrm{P}-\mathrm{H}$ chemical shifts and characteristic ${ }^{1} \mathrm{~J}_{\mathrm{HP}}$ coupling constants (ca. $600 \mathrm{~Hz}$ ). In the ${ }^{31} \mathrm{P}$ NMR spectrum, there were three different monophosphorus components confirmed to be compounds 2-4. Two moles of acetate 6 were detected compared to one mole of the total amount of phosphites 2-4 which was the expected result. Interestingly, the decomposition mixture of $\mathbf{1 a}$ contained not only monoethyl phosphite $\mathbf{2}$ and phosphite $\mathbf{4}$ but also monomethyl derivative $\mathbf{3}$ (according the ${ }^{31} \mathrm{P}$ NMR spectrum, the ratio was approx.: 1:0.86:1, respectively, see Supporting Information File 1, S13). The formation of this monomethyl phosphite 3 under the conditions used (see Scheme 2, procedure ii) can be explained based on: 1) partial transesterification of bisphosphonate 1a before degradation of P-C-P bridge, 2) partial esterification of phosphonate group after the carbonate groups $\left(\mathrm{R}^{3}\right)$ decomposition from compound 1a (this is proposed to occur rapidly after the addition of $40 \%$

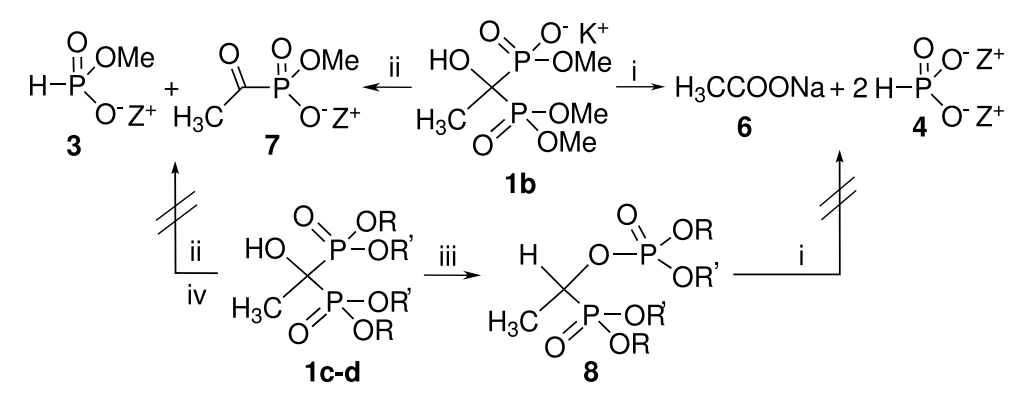

Scheme 1: Degradation of trimethyl ester of etidronate (1b) and stability of the tetramethyl ester $\left(\mathbf{1 c}, R^{\prime}=R^{\prime}=M e\right)$ and $P, P^{\prime}$-dimethyl ester $\left(1 d^{\prime}, R=M e\right.$, $\mathrm{R}^{\prime}=\mathrm{Na}^{+}$) of etidronate. Reagents and conditions: i) 1 drop of $6 \mathrm{M} \mathrm{NaOH}, \mathrm{H}_{2} \mathrm{O}, 1 \mathrm{~h}$, rt, (measured pH was $\geq 11$ ); ii) 5 equiv triethylamine, $\mathrm{H}_{2} \mathrm{O}, 1 \mathrm{~h}, 60$ ${ }^{\circ} \mathrm{C}$; iii) when $\mathrm{R}=\mathrm{R}^{\prime}=\mathrm{Me}\left(\right.$ (1c), 1 eq, triethylamine, $\mathrm{H}_{2} \mathrm{O}, 10$ min. ca. $98 \%$ conversion. iv) when $\mathrm{R}=\mathrm{Me}, \mathrm{R}^{\prime}=\mathrm{Na}^{+}(\mathbf{1 d}), 5$ equiv $\mathrm{NaOH}, \mathrm{H}_{2} \mathrm{O}$, overnight, reflux. 


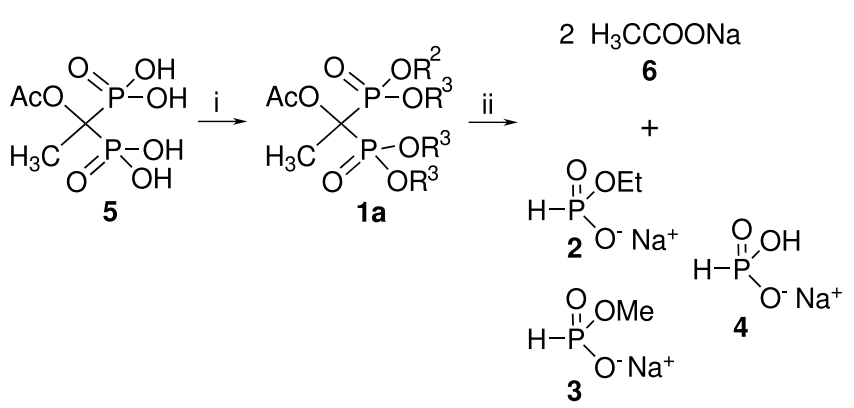

Scheme 2: Preparation of BP derivative 1a $\left(R^{2}=E t, R^{3}=C(O) O E t\right)$ and its degradation to acetate $\mathbf{6}$ and phosphites 2-4. Reagents and conditions: i) excess $\mathrm{CIC}(\mathrm{O}) \mathrm{OEt}, 6$ equiv $\mathrm{Na}_{2} \mathrm{CO}_{3}$, reflux, overnight, $55 \%$; ii) 4 equiv $\mathrm{NaOH}\left(40 \% \mathrm{NaOH}\right.$ in $\left.\mathrm{H}_{2} \mathrm{O}\right), \mathrm{MeOH}, 30 \mathrm{~min}$, rt.

$\mathrm{NaOH}$ ) and before the degradation of P-C-P bridge, 3) partial transesterification of $\mathbf{2}$, and 4 ) esterification of $\mathbf{4}$ (see Scheme 2).

These unexpected degradation results we observed for the HEBPA derivative 1a led us to examine what would happen to more simple derivatives of HEBPA, such as trimethyl (1b), tetramethyl (1c) and P,P'-dimethyl (1d) esters of etidronate under the same kinds of conditions (see Scheme 1). Compounds 1b-d were prepared as reported elsewhere [20,26-28]. Again very surprising results were obtained. Trimethyl ester of etidronate (1b) was degraded to the acetate $\mathbf{6}$ and phosphorous acid salt $\mathbf{4}$, under even milder conditions than the degradation of $\mathbf{1 a}$ (50 $\mathrm{mg}$ of $\mathbf{1 b}$ in $1 \mathrm{ml} \mathrm{H} \mathrm{H}_{2} \mathrm{O}$ and 1 drop of $6 \mathrm{M} \mathrm{NaOH}$ was stirred for 1 hour at $\mathrm{rt}$; measured $\mathrm{pH}$ was $\geq 11$; see Scheme 1). Tetramethyl (1c) or P,P'-dimethyl ester were not degraded under the same conditions, only the formation of phosphonate-phosphate derivative $\mathbf{8}$ from 1c was observed as expected in the light of the earlier results concern the rearrangement process [17,20,21, 29-32]. This rearrangement of $\mathbf{1 c}$ to $\mathbf{8}$ was observed to happen rapidly and almost completely (98\% conversion) when 1 equiv of triethylamine was present in water (see Scheme 1).
Compound $\mathbf{1 b}$ was selectively degraded to the phosphite $\mathbf{3}$ and acetyl phosphonate $\mathbf{7}$ when $\mathbf{5}$ equiv of triethylamine was used in $\mathrm{H}_{2} \mathrm{O}$ (see Scheme 1). Dialkyl acetylphosphonates and dialkyl phosphites are common starting materials for the synthesis of tetraalkyl esters of HEBPA [26,27], but this is the first time when the "reverse" synthesis has been reported. P,P'-dimethyl ester 1d did not degrade to compounds $\mathbf{3}$ and $\mathbf{7}$ or $\mathbf{6}$ and $\mathbf{4}$ even when refluxed overnight with 5 equiv $\mathrm{NaOH}$ in $\mathrm{H}_{2} \mathrm{O}$.

The decomposition mechanism for $\mathbf{1 b}$ can be explained in two ways; either via a decomposition mechanism resembling the reversible route of the formation of tetraesters (see Scheme 3 route a), since e.g., 1c, are prepared from phosphites, $\mathrm{H}-\mathrm{P}(\mathrm{O})(\mathrm{OMe})_{2}$, and phosphonates, $\mathrm{MeCOP}(\mathrm{O})(\mathrm{OMe})_{2}$, or route b resembling the rearrangement process [19]. The driving force in both reactions is the formation of three charged molecules from one P-C-P compound since this is a highly entropically favoured process. Decomposition of the first P-C bond starts with deprotonation of the hydroxyl group followed by elimination of the methyl phosphite and the formation of ketone (route a) or by nucleophilic attack of the oxygen of the ionized phosphate on the bridging carbon to release dimethyl phosphite and the oxirane ring containing derivative (route b). In route a,

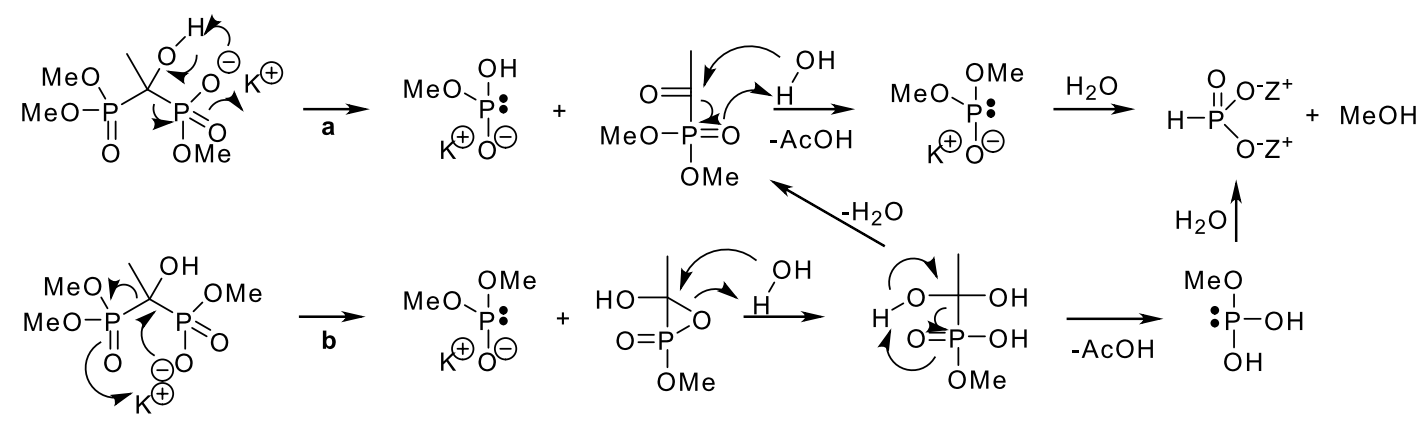




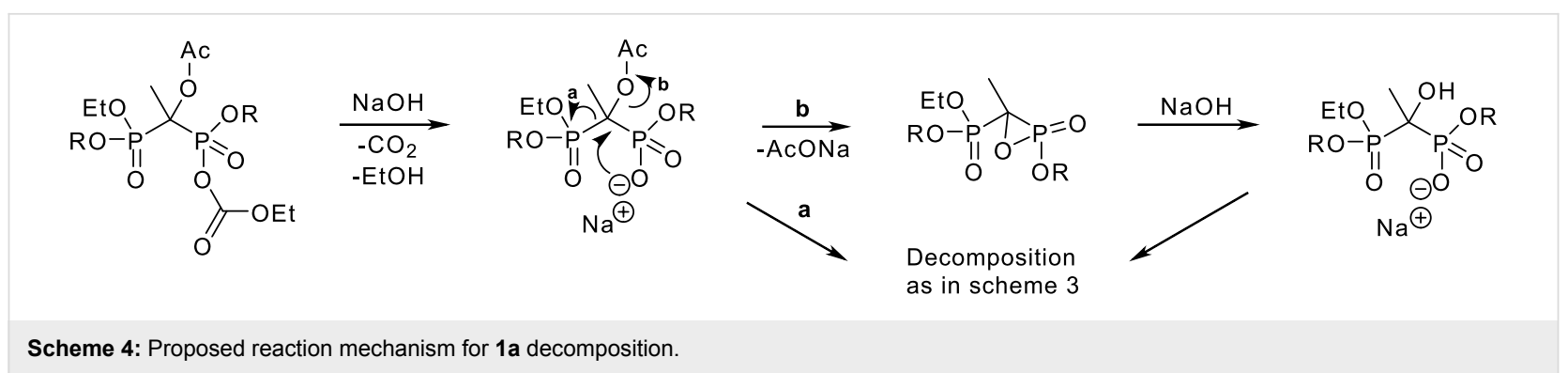

water or hydroxide ion attacks the carbonyl carbon and P-C bond cleavage occurs giving rise to acetic acid and dimethyl phosphite which can undergo a further reaction with water or hydroxide to give methyl phosphite. In route $\mathbf{b}$, the attack of water on the carbon of oxirane ring yields hydrate followed by elimination of methyl phosphite and acetic acid. We believe that route $\mathbf{a}$ is more probable, since during the reaction with a weaker base, such as triethylamine, only the first P-C bond is cleaved and products $\mathbf{3}$ and $\mathbf{7}$ are observed. On the other hand, decomposition of $\mathbf{1 a}$ is more likely to follow route $\mathbf{b}$.

The proposed decomposition mechanism for 1a (see Scheme 4) is more complicated. The reaction starts with the hydrolysis of one carbonate ester leading to a monoanion comparable to $\mathbf{1 b}$. After this step, the decomposition can continue following routes that are similar to either route $\mathbf{a}$ or route $\mathbf{b}$ in Scheme 3. The other possibility, route b (in Scheme 4), is a nucleophilic attack of oxygen to the bridging carbon and the formation of an oxirane ring containing derivative, since the adjacent acetate group is a rather good leaving group. Subsequently, P-C-bond decomposition will follow the same mechanism as reported in Scheme 3.

The initial reaction in Scheme 3 also explains the formation of rearranged product $\mathbf{8}$ from tetraester $\mathbf{1 c}$ (this rearrangement is proposed to happen via oxirane ring) [19], since the charged oxygen is a good nucleophile compared to $\mathrm{OH}$-group and far better than oxygen bound to phosphorus with a double bond $(\mathrm{P}=\mathrm{O})$.

All of the compounds were easily identified by their ${ }^{1} \mathrm{H},{ }^{13} \mathrm{C}$ and ${ }^{31} \mathrm{P}$ NMR spectra. In ${ }^{31} \mathrm{P}$ NMR signals for the phosphites 2 , 3 and 4 were $6.26 \mathrm{ppm}, 8.47 \mathrm{ppm}$ and $5.81 \mathrm{ppm}$, respectively and $0.10 \mathrm{ppm}$ for acetylphosphonate 7 . These values were comparable to those reported earlier [27].

\section{Conclusion}

In conclusion, a novel carbonate derivative of etidronate (1a) was prepared by the reaction of acetylated etidronic acid with ethyl chloroformate and sodium carbonate. Compound 1a was found to undergo remarkably facile cleavage of the P-C bond under mild basic conditions. The trimethyl ester of etidronate (1b) was also found to undergo readily P-C bond cleavage under similar conditions. The trimethyl ester of etidronate (1b) was also observed to be degraded to phosphite $\mathbf{3}$ and acetylphosphonate 7 when mixed in $\mathrm{H}_{2} \mathrm{O}$ containing 5 equiv of triethylamine. Some mechanisms to explain these behaviors have been proposed though further investigations will be necessary to confirm the proposed degradation pathways.

\section{Supporting Information}

\section{Supporting Information File 1}

Unexpected degradation of bisphosphonate P-C-P bridge under mild conditions. Experimental procedures, full spectroscopic data and NMR spectra for the novel compound 1a and NMR spectra for the degradation studies of $\mathbf{1 a}$ and $\mathbf{1 b}$.

[http://www.beilstein-journals.org/bjoc/content/ supplementary/1860-5397-4-7-S1.pdf]

\section{Acknowledgments}

Authors would like to thank Mrs. Maritta Salminkoski for her expert technical assistance for performing most of the experiments reported here, and Mrs. Katja Höppi for the ESI-MS analysis.

\section{References}

1. Fleisch, H. Bisphosphonates in Bone Disease: From the Laboratory to the Patient; The Parthenon Publishing Group Inc.: New York, 1995.

2. Papapoulos, S. E.; Landman, J. O.; Bijvoet, O. L. M.; Löwik, C. W. G. M.; Valkema, R.; Pauwels, E. K. J.; Vermeij, P. Bone 1992, 13 (Suppl. 1), S41-S49.

3. Yates, A. J.; Rodan, G. A. Drug Discovery Today 1998, 3, 69-78. doi:10.1016/S1359-6446(97)01134-3

4. Papapoulos, S. E. Am. J. Med. 1993, 95 (5, Suppl. 1), S48-S52. doi:10.1016/0002-9343(93)90383-Z

5. Giannini, S.; D'Angelo, A.; Sartori, L.; Passeri, G.; Dalle Carbonare, L.; Crepaldi, G. Obstet. Gynecol. 1996, 88, 431-436. doi:10.1016/0029-7844(96)00171-8

6. Fleisch, H. Drugs 1991, 42, 919-944. 
7. Szajnman, S. H.; Montalvetti, A.; Wang, Y.; Docampo, R.; Rodriguez, J. B. Bioorg. Med. Chem. Lett. 2003, 13, 3231-3235. doi:10.1016/S0960-894X(03)00663-2

8. Szajnman, S. H.; Bailey, B. N.; Docampo, R.; Rodriguez, J. B. Bioorg. Med. Chem. Lett. 2001, 11, 789-792. doi:10.1016/S0960-894X(01)00057-9

9. Martin, M. B.; Sanders, J. M.; Kendrick, H.; de Luca-Fradley, K.; Lewis, J. C.; Grimley, J. S.; Van Brussel, E. M.; Olsen, J. R.; Meints, G. A.; Burzynska, A.; Kafarski, P.; Croft, S. L.; Oldfield, E. J. Med. Chem. 2002, 45, 2904-2914. doi:10.1021/jm0102809

10. Garzoni, L. R.; Caldera, A.; Nazareth L. Meirelles, M.; Castro, S. L.; Docampo, R.; Meints, G. A.; Oldfield, E.; Urbina, J. A. Int. J. Antimicrob. Agents 2004, 23, 273-285. doi:10.1016/j.jantimicag.2003.07.020

11. Garzoni, L. R.; Waghabi, M. C.; Baptista, M. M.; Castro, S. L.; Nazareth L. Meirelles, M.; Britto, C. C.; Docampo, R.; Oldfield, E.; Urbina, J. A. Int. J. Antimicrob. Agents 2004, 23, 286-290. doi:10.1016/j.jjantimicag.2003.07.019

12. Ylitalo, R. Gen. Pharmacol. 2000, 35, 287-296. doi:10.1016/S0306-3623(01)00121-5

13. Kajander, E. O. Lett. Appl. Microbiol. 2006, 42, 549-552. doi:10.1111/j.1472-765X.2006.01945.x

14. Aho, K.; Soininen, T.; Turhanen, P. A.; Kajander, E. O.; Vepsäläinen, J. J. Unpublished results.

15. Major, P. P.; Lipton, A.; Berenson, J.; Hortobagyi, G. Cancer (N. Y.) 2000, 88, 6-14. doi:10.1002/(SICl)1097-0142(20000101)88:1<6::AID-CNCR3>3.0.CO; 2-D

16. Turhanen, P. A.; Niemi, R.; Peräkylä, M.; Järvinen, T.; Vepsäläinen, J. J. Org. Biomol. Chem. 2003, 1, 3223-3226. doi:10.1039/b305979k

17. Turhanen, P. A.; Vepsäläinen, J. J. Synthesis 2005, 2119-2121. doi:10.1055/s-2005-869984

18. Turhanen, P. A.; Vepsäläinen, J. J. Synthesis 2005, 3063-3066. doi:10.1055/s-2005-916032

19. Niemi, R.; Turhanen, P.; Vepsäläinen, J.; Taipale, H.; Järvinen, T. Eur. J. Pharm. Sci. 2000, 11, 173-180. doi:10.1016/S0928-0987(00)00099-3

20. Turhanen, P. A.; Ahlgren, M. J.; Järvinen, T.; Vepsäläinen, J. J. Synthesis 2001, 633-637. doi:10.1055/s-2001-12353

21. Turhanen, P. A.; Vepsäläinen, J. J. Synthesis 2004, 992-994. doi:10.1055/s-2004-822345

22. Turhanen, P. A.; Vepsäläinen, J. J. Beilstein J. Org. Chem. 2006, 2, No. 2. doi:10.1186/1860-5397-2-2

23. Vepsäläinen, J. J. Curr. Med. Chem. 2002, 9, 1201-1208.

24. Szymczak, M.; Szymańska, A.; Stawiński, J.; Boryski, J.; Kraszewski, A. Org. Lett. 2003, 5, 3571-3573. doi:10.1021/ol035166u

25. Szajnman, S. H.; García Liñares, G.; Moro, P.; Rodriguez, J. B. Eur. J. Org. Chem. 2005, 3687-3696. doi:10.1002/ejoc.200500097

26. Nicholson, D. A.; Vaughn, H. J. Org. Chem. 1971, 36, 3843-3845. doi:10.1021/jo00823a621

27. Turhanen, P. A.; Ahlgren, M. J.; Järvinen, T.; Vepsäläinen, J. J. Phosphorus, Sulfur Silicon Relat. Elem. 2001, 170, 115-133. doi:10.1080/10426500108040589

28. Van Gelder, J. M.; Breuer, E.; Ornoy, A.; Schlossman, A.; Patlas, N.; Golomb, G. Bone 1995, 16, 511-520. doi:10.1016/8756-3282(95)00081-N
29. Vachal, P.; Hale, J. J.; Lu, Z.; Streckfuss, E. C.; Mills, S. G.; MacCoss, M.; Yin, D. H.; Algayer, K.; Manser, K.; Kesisoglou, F.; Ghosh, S.; Alani, L. L. J. Med. Chem. 2006, 49, 3060-3063. doi:10.1021/jm060398v

30. Fitch, S. J.; Moedritzer, K. J. Am. Chem. Soc. 1962, 84, 1876-1879. doi:10.1021/ja00869a022

31. Ruel, R.; Bouvier, J.-P.; Young, R. N. J. Org. Chem. 1995, 60, 5209-5213. doi:10.1021/jo00121a044

32. Tromelin, A.; El Manouni, D.; Burgada, R. Phosphorus Sulfur Relat. Elem. 1986, 27, 301-312. doi:10.1080/03086648608072784

\section{License and Terms}

This is an Open Access article under the terms of the Creative Commons Attribution License (http://creativecommons.org/licenses/by/2.0), which permits unrestricted use, distribution, and reproduction in any medium, provided the original work is properly cited.

The license is subject to the Beilstein Journal of Organic Chemistry terms and conditions: (http://www.beilstein-journals.org/bjoc)

The definitive version of this article is the electronic one which can be found at: doi:10.1186/1860-5397-4-7 